\title{
Biopsy of Duodenum
}

National Cancer Institute

\section{Source}

National Cancer Institute. Biopsy of Duodenum. NCI Thesaurus. Code C51683.

Removal of tissue from the duodenum for microscopic examination, using an endoscope. 